\title{
Toxins of the Gonyaulax sp. and Infested Bivalves in Owase Bay
}

\author{
Yasukatsu Oshima, ${ }^{* 1}$ William E. Fallon, ${ }^{* 1}$ Yuzuru Shimrzu, ${ }^{* 1}$ \\ Tamao NoGuchI, ${ }^{* 2}$ and Yoshiro Hashimoto*2
}

(Received March 4, 1976)

\begin{abstract}
The algal specimens, mussels and short-necked clams were collected during or immediately after the outbreak of Gonyaulax sp. at Owase Bay in 1975. Extraction and purification of the toxins were carried out according to the method used for the isolation of the toxins in softshell clams and cultured $G$. tamarensis. By a combination of Sephadex G-15, Bio-Gel $\mathbf{P}-2$ and Bio-Rex 70 column chromatography, six toxins were isolated from each specimen. Of these, five were identified as saxitoxin, GTX GTX $_{1}^{\prime}, \mathrm{GTX}_{2}$, and $\mathrm{GTX}_{5}$, respectively, which were found in $G$. tamarensis. The major toxin JGX1 was found to be a new one.
\end{abstract}

In January, 1975, the occurrence of a Gonyaulax sp. blóom was reported at Owase Bay, Mie Prefecture, Japan. In the preceding paper the biological nature of the bloom and a preliminary study of the toxins were reported. ${ }^{1 /}$ This paper will report the purification and identification of the toxins in the dinoflagellate, mussels and shortnecked clams according to the method used for the isolation of the toxins in softshell clams Mya arenaria and cultured G. tamarensis cells. ${ }^{2}$

\section{Materials and Methods}

The collection and preservation of the dinoflagellate specimen, short-necked clams Tapes (Amygdala) japonica and mussels Mytilus sp. were described in the preceding report. ${ }^{1)}$ Extraction was carried out from $200 \mathrm{~g}$ each of the shucked short-necked clams and mussels with $400 \mathrm{ml}$ of $80 \%$ ethanol adjusted to $\mathrm{pH} 2.0$ with $\mathrm{HCl}$. The extract was concentrated and washed with chloroform. Three hundred milliliters of condensed dinoflagellate suspension, which was kept frozen after being adjusted to $\mathrm{pH} 2.0$, was thawed and centrifuged. The supernatant was adjusted to $\mathrm{pH} 4.2$ with $1 \mathrm{~N} \mathrm{NaOH}$, evaporated to dryness, and then extracted twice with $5 \mathrm{ml}$ of $80 \%$ ethanol.

Sephadex G-15 (Pharmacia Fine Chemicals) and Bio-Gel P-2 (minus 400 mesh, Bio Rad Laboratories) columns were prepared under water and eluted with water followed by $0.05 \mathrm{~N}$ acetic acid. Prior to chromatography, the sample solution was adjusted to pH 6.5 with $0.1 \mathrm{~N} \mathrm{NaOH}$.

High speed liquid chromatography (HSLC) was carried out using a Model Milroyal

*1 Department of Pharmacognosy, College of Pharmacy, University of Rhode Island, Kingston, Rhode Island 02881, U.S.A. (大島泰克・William E. FALLON・清水 筷：ロートフイランド大学)

*2 Laboratory of Marine Biochemistry, Faculty of Agriculture, The University of Tokyo, Bunkyo-ku, Tokyo (野口玉雄・橋本芳郎: 東京大学農学部) 
D constant flow pump (Milton Roy Co.) and glass columns which were prepared by packing Bio-Rex 70 (acidic form, minus 400 mesh, Bio Rad Laboratories). The toxins were eluted with a linear gradient of acetic acid from 0 to $0.03 \mathrm{~N}$ and then with $0.02 \mathrm{~N}$ $\mathrm{HCl}$.

Purified toxins were compared with $G$. tamarensis toxins ${ }^{2)}$ on Silica Gel GF (Analtech, Inc.) and Silica Gel 60 (EM Laboratories, Inc.) precoated plates with solvent systems of $t$ - butanol: acetic acid: water $(2: 1: 1)$ and pyridine: ethylacetate: water: acetic acid (75:25:30:15), respectively. Electrophoresis (PE) was carried out on cellulose acetate strips (Shleicher \& Schuell, Inc., No. 2500) in $0.083 \mathrm{~N}$ Tris- $\mathrm{HCl}$ buffer pH 8.7 , at $200 \mathrm{~V}$ (constant) and $0.2 \mathrm{~mA} / \mathrm{cm}$ for 1 to $3 \mathrm{hr}$. Toxins were detected by spraying with $1 \%$ hydrogen peroxide and heating at $120^{\circ} \mathrm{C}$ for $15 \mathrm{~min}$. Fluorescent spots were viewed under UV light $(350 \mathrm{~nm})$.

Toxicity assays were done according to the USPHS method originally described by Sommer and Meyer $^{3)}$ using the Death-Time/Dose curve reported in the previous work. ${ }^{2)}$

\section{Results}

Purification of mussel toxins The mussel extract, which showed a total toxicity of 7,000 MU, was fractionated into two toxic fractions (the major part, 5,000 MU, eluted with water; and the minor part, 1,200 MU, eluted with acetic acid), by Sephadex G-15 chromatography (column size: $2.65 \times 100 \mathrm{~cm}$ ).

The major toxic fraction was chromatographed on a Bio-Gel P-2 column $(2.5 \times$ $40 \mathrm{~cm}$ ). The elution pattern of toxins from the Bio-Gel P-2 column is shown in Fig. 1a. Out of the total 3,300 MU charged on the column, 1,100 MU were eluted with water and 1,900 MU with $0.05 \mathrm{~N}$ acetic acid. The rest of toxicity was found in the water elute. The toxins eluted with acetic acid from Sephadex G-15 column were rechromatographed on a Bio-Gel P-2 column $(1.0 \times 40 \mathrm{~cm})$. All the toxin was bound well on the column in water and elution with $0.05 \mathrm{~N}$ acetic acid afforded $670 \mathrm{MU}$ of a mixture of toxins.

Toxic fractions eluted with acetic acid from the both Bio-Gel P-2 columns were combined and fractionated by HSLC using a Bio-Rex 70 column $(0.5 \times 60 \mathrm{~cm})$. The major part of toxins (1,500 MU) was eluted with acetic acid and separated from the minor part $(290 \mathrm{MU})$ which was later eluted with $0.02 \mathrm{~N} \mathrm{HCl}$ as a single peak. The former fraction was rechromatographed on a longer column $(0.6 \times 100 \mathrm{~cm})$. The elution pattern of these toxins is shown in Fig. 2a. The presence of five toxins, tentatively named JGXl-5, in order of elution, were observed by TLC and PE. The three peaks shown in Fig. 2a corresponded to the major toxins JGX1, JGX3, and JGX5. In addition, two minor toxins were found to overlap the main peaks; JGX2 was eluted concomitantly with JGX1 and JGX3, while JGX4 was eluted JGX3 and JGX5. Another toxin (JGX6) 


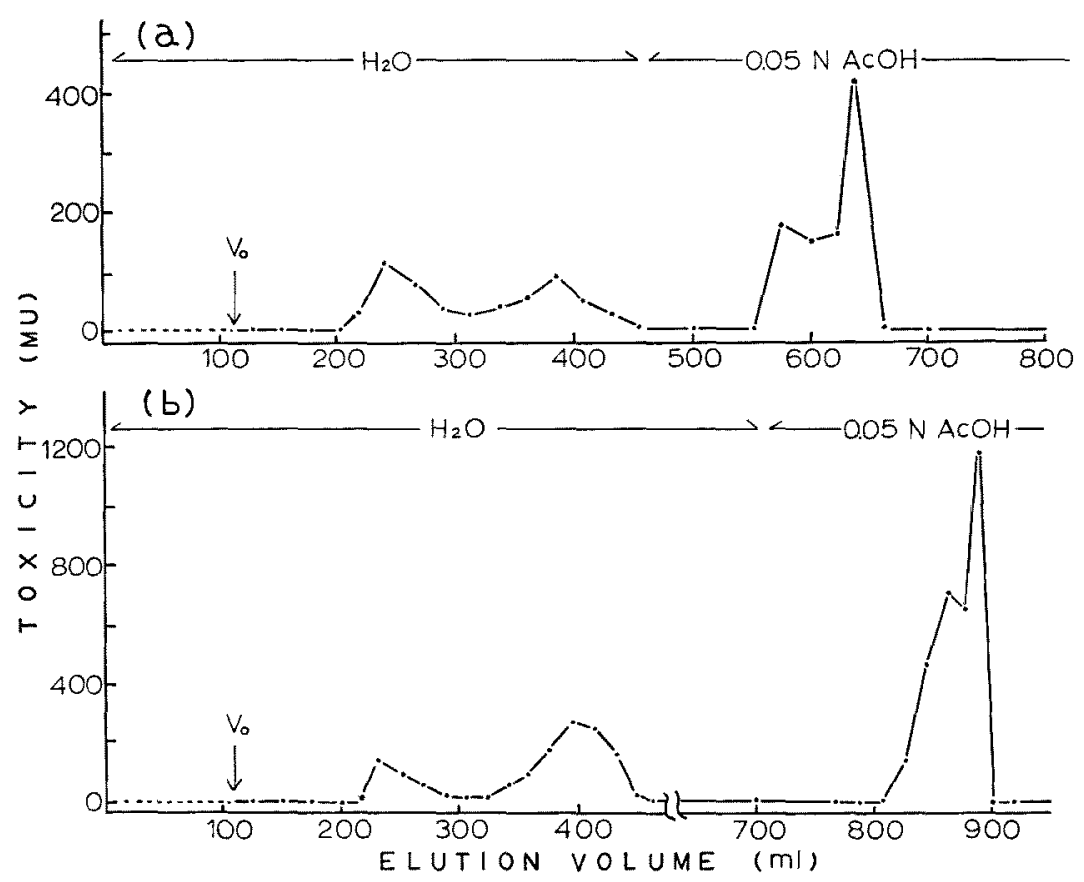

Fig. 1. Bio-Gel P-2 column chromatography.

(a) Mussel toxin (3,300 MU) and (b) Gonyaulax sp. toxin (4,800 MU) were chromatographed on the $2.5 \times 40 \mathrm{~cm}$ column at a flow rate of $0.6 \mathrm{~m} / / \mathrm{min}$.

was also isolated by rechromatography of the $\mathrm{HCl}$ eluate from the first Bio-Rex 70 column.

Purification of short-necked clam toxins The extract from the short-necked clams having an activity of 3,500 MU was subjected to Sephadex G-15 column chromatography. Since only a portion of the toxicity was retained on the gel, probably due to the interference of a large amount of coexisting substances, the Sephadex filtration was repeated and a total of $2,200 \mathrm{MU}$ of the bound toxins was obtained by $0.05 \mathrm{M}$ acetic acid elution.

Sephadex G-15 purified toxins (700 MU) were reapplied onto a Bio-Gel P-2 column $(1.0 \times 40 \mathrm{~cm})$. All the toxins were found in the acetic acid eluate. This fraction was found to contain six components identical to those found in mussels and dinoflagellate as analyzed by TLC and electrophoresis.

Purification of Gonyaulax sp. toxins The extract from the bloom $(4,800 \mathrm{MU})$ was directly applied onto a Bio-Gel P-2 column $(2.5 \times 40 \mathrm{~cm})$. The elution pattern is shown in Fig. 1b. The combined acetic acid eluates (3,700 MU) were rechromatographed on a smaller Bio-Gel column $(1.0 \times 40 \mathrm{~cm})$, and $3,000 \mathrm{MU}$ of toxins were recovered. This preparation was purified further by HSLC using a Bio-Rex 70 column $(0.6 \times 100 \mathrm{~cm})$. The elution pattern with acetic acid was identical to that of the mussel toxins (Fig. 2b). 


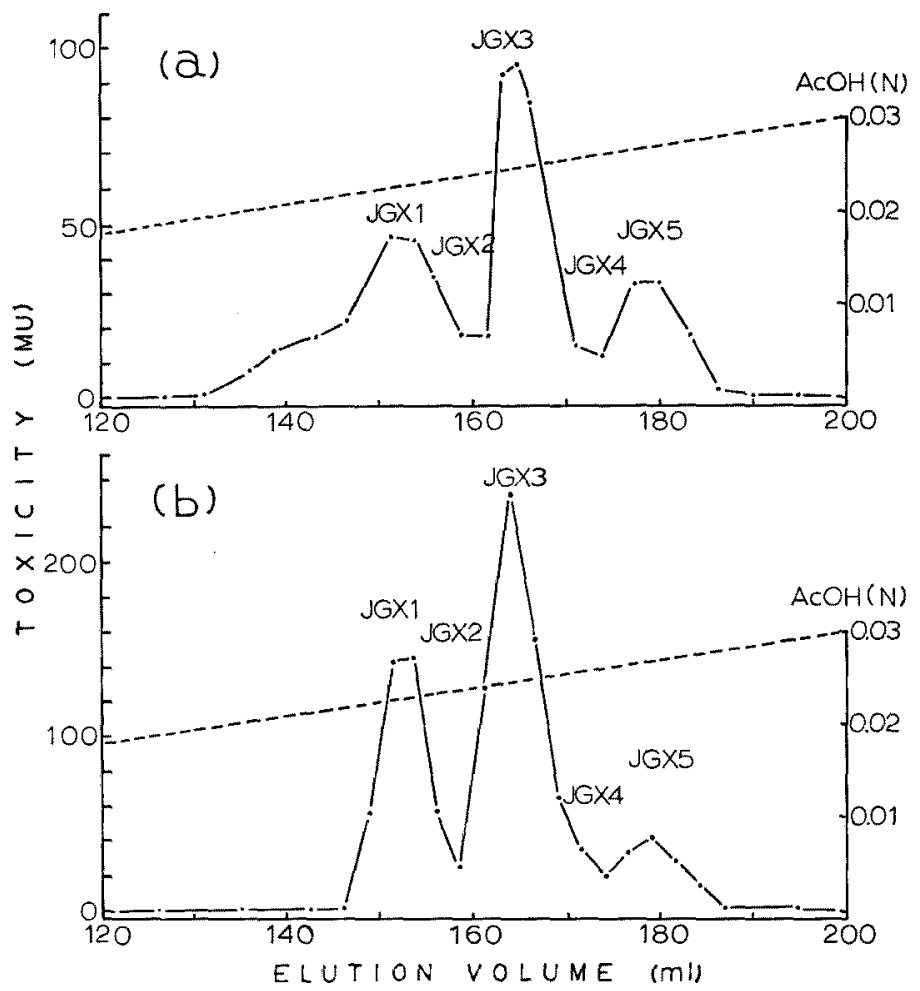

Fig. 2. Bio-Rex 70 column chromatography.

(a) Mussel toxin (1,090 MU) and (b) Gonyaulax sp. toxin (3,000 MU) were chromatographed on the $0.6 \times 100 \mathrm{~cm}$ column at a flow rate of $1 \mathrm{ml} / \mathrm{min}$. The dotted line indicates the concentration of acetic acid.

Furthermore, on TLC and PE, the same five toxins (JGX1-5) appeared at the same elution volume as did the mussel toxins. In the fraction eluted later with $0.02 \mathrm{~N} \mathrm{HCl}$ the toxin corresponding to JGX6 (100 MU) was also recognized.

Table 1. Chromatography and electrophoretic behavior of isolated toxins

\begin{tabular}{|c|c|c|c|c|c|}
\hline Toxins & $\begin{array}{l}\text { Elution order from } \\
\text { Bio-Rex } 70 \text { column }\end{array}$ & $\mathrm{Rf}^{* 1}$ & $\mathrm{Rf}^{* 2}$ & $\underset{\mathrm{Rm}^{* 3}}{\mathrm{PE}}$ & $\begin{array}{l}\text { Toxins } \\
\text { Identified }\end{array}$ \\
\hline JGXI & 1 & 0.61 & 0.52 & 0.28 & - \\
\hline $\mathrm{JGX} 2$ & 2 & 0.81 & 0.65 & 0 & GTX $_{1}^{\prime}$ \\
\hline JGX3 & 3 & 0.90 & 0.70 & 0.16 & GTX $_{1}$ \\
\hline $\mathrm{JGX} 4$ & 4 & 0.69 & 0.61 & 0.28 & $\mathrm{GTX}_{3}$ \\
\hline JGX5 & 5 & 0.81 & 0.65 & 0.56 & $\mathrm{GTX}_{2}$ \\
\hline JGX6 & 6 & 0.62 & 0.51 & 1.00 & saxitoxin \\
\hline
\end{tabular}

*1 Silica Gel 60: pyridine, ethylacetate, water, acetic acid $(75: 25: 30: 15)$.

*2 Silica Gel GF: t-butanol, acetic acid, water $(2: 1: 1)$.

*3 Relative mobility on cellulose acetate strip in Tris- $\mathrm{HCl}$ buffer $\mathrm{pH} 8.7$, at $200 \mathrm{~V}$ (constant) and $0.2 \mathrm{~mA} / \mathrm{cm}$ for $1 \mathrm{hr}$ to that of saxitoxin. 
Thin-layer chromatography and paper electrophoresis The results of TLC and PE of the toxins from mussels and Gonyaulax sp. are summarized in Table 1. JGX2, JGX3, JGX4, JGX5 and JGX6 showed the same mobilities as GTX ${ }_{1}^{\prime *}$, GTX $_{1}$, GTX $_{3}$, GTX $_{2}$ and saxitoxin, respectively. JGX2 $\left(\mathrm{GTX}_{1}{ }^{\prime}\right)$ and JGX5 $\left(\mathrm{GTX}_{2}\right)$ have close Rf values on TLC in both solvent systems, but they were clearly distinguishable from each other by PE.

\section{Discussion}

The purification methods used for $G$. tamarensis toxins were also effective for this study and the previous finding that the major toxins in short-necked clams were different from saxitoxin, the sole toxin reported in G. catenella was confirmed. Although the organism was tentatively identified as $G$. catenella, ${ }^{1}$ it was revealed that the composition of toxins in the Gonyaulax sp. bloom at Owase Bay is similar to that of G. tamarensis. From the behavior of the toxins on HPLC, TLC and PE, we conclude that five toxins (JGX 2-6) are identical to those found in G. tamarensis. However, there were two points of difference between the paralytic shellish poisoning toxin in Japan and New England. The former contained a significant amount of an additional toxin (JGX1), and also the relative concentration of $\mathrm{GTX}_{1}$ in the mussel and Gonyaulax sp. toxins from Japan was far greater than that in $G$. tamarensis.

In the column chromatography on Sephadex G-15 and Bio-Gel P-2, the crude toxin was fractionated into unbound and bound toxins. The results of previous studies $^{4,5)}$ on $G$. tamarensis toxins suggest that a large amount of salts or other contaminants in the extract partially prevented the adsorption of toxins onto both gels and caused the apparent fractionation in the column chromatography. Nevertheless, the possibility that toxin(s) other than JGX1-6 exist in the unbound portion is not excluded, because toxins in the water eluted fraction could not be characterized directly by TLC and PE due to a large amount of residues in the fractions.

After rechromatography on Bio-Rex 70 , all the toxic fractions appeared as almost invisible residues. A determination of specific toxicities was not achieved due to the scarcity of the compounds.

\section{Acknowledgments}

This work was supported by HEW Grant FD-00619, the Sea Grant Program, University of Rhode Island, and a grant from the Ministry of Education, Japan.

\section{References}

1) Y. Hashmoto, T. Noguchi, and R. Adach: This Bull., 42, 671-676 (1976).

\footnotetext{
* This toxin appears just before $\mathrm{GTX}_{1}$ in Bio-Rex 70 column chromatography. However, the
} toxicity of this compound was not confirmed before (See the legend in Fig. 2 of the previous report) ${ }^{2)}$ 
2) Y. Shimizu, M. Alam, Y. Oshima, and W. E. Fallon: Biochem. Biophys. Res. Commun., 66, 731-737 (1975).

3) H. Sommer and K. F. Meyer: Arch. Pathol., 24, 560-598 (1937).

4) Y. Shimizu, M. Alam, and W. E. FALLON: in Proceedings of the First International Conference on Toxic Dinoflagellate Blooms, 275-285, the Massachusetts Science and Technology Foundation, Massachusetts (1975).

5) L. J. Buckley, M. IKaWA, and J. J. SASNer, Jr.: ibid., 423-431 (1975). 